\title{
(2) OPEN ACCESS \\ Two-year neurodevelopmental outcome in children born extremely preterm: the EPI-DAF study
}

\author{
Pauline E van Beek (D) , ${ }^{1}$ Monique Rijken, ${ }^{2}$ Lisa Broeders, ${ }^{3}$ Hendrik J ter Horst, ${ }^{4}$ \\ Corine Koopman-Esseboom, ${ }^{5}$ Ellen de Kort, ${ }^{1}$ Céleste Laarman, ${ }^{6}$ \\ Susanne M Mulder-de Tollenaer, ${ }^{7}$ Katerina Steiner, ${ }^{8}$ Renate MC Swarte, ${ }^{9}$ \\ Elke van Westering-Kroon, ${ }^{10} \mathrm{~S}$ Guid Oei, ${ }^{11,12}$ Aleid G Leemhuis, ${ }^{13}$ \\ Peter Andriessen (D) ${ }^{14,15}$ on behalf of the EPI-DAF study group
}

- Additional supplemental material is published online only. To view, please visit the journal online (http://dx.doi. org/10.1136/archdischild2021-323124).

For numbered affiliations see end of article.

Correspondence to Pauline E van Beek, Department of Neonatology, Máxima Medisch Centrum locatie Veldhoven, Veldhoven, NoordBrabant, Netherlands; pauline.van.beek@mmc.nl

Received 31 August 2021 Accepted 29 January 2022

Check for updates

(c) Author(s) (or their employer(s)) 2022. Re-use permitted under CC BY-NC. No commercial re-use. See rights and permissions. Published by BMJ.

To cite: van Beek PE, Rijken $\mathrm{M}$, Broeders $\mathrm{L}$, et al. Arch Dis Child Fetal Neonatal Ed Epub ahead of print: [please include Day Month Year] doi:10.1136/archdischild 2021-323124

\section{ABSTRACT \\ Objective In 2010, the Dutch practice regarding} initiation of active treatment in extremely preterm infants was lowered from 25 completed weeks' to 24 completed weeks' gestation. The nationwide Extremely Preterm Infants - Dutch Analysis on Follow-up Study was set up to provide up-to-date data on neurodevelopmental outcome at 2 years' corrected age (CA) after this guideline change.

Design: National cohort study.

Patients All live born infants between $24^{0 / 7}$ weeks' and $26^{6 / 7}$ weeks' gestational age who were 2 years' $C A$ in 2018-2020.

Main outcome measure Impairment at 2 years' CA, based on cognitive score (Bayley-III-NL), neurological examination and neurosensory function.

Results 651 of 991 live born infants (66\%) survived to 2 years' CA, with data available for 554 (85\%). Overall, $62 \%$ had no impairment, $29 \%$ mild impairment and $9 \%$ moderate-to-severe impairment (further defined as neurodevelopmental impairment, NDI). The percentage of survivors with NDI was comparable for infants born at 24 weeks', 25 weeks' and 26 weeks' gestation. After multivariable analysis, severe brain injury and low maternal education were associated with higher odds on NDI. NDI-free survival was $48 \%, 67 \%$ and $75 \%$ in neonatal intensive care unit (NICU)-admitted infants at 24, 25 and 26 weeks' gestation, respectively.

Conclusions Lowering the threshold has not been accompanied by a large increase in moderate-to-severely impaired infants. Among live-born and NICU-admitted infants, an increase in NDI-free survival was observed from 24 weeks' to 26 weeks' gestation. This description of a national cohort with high follow-up rates gives an accurate description of the range of outcomes that may occur after extremely preterm birth.

\section{INTRODUCTION}

The number of preterm deliveries has increased over the last decades, with increasing survival rates in the neonatal intensive care unit (NICU). ${ }^{12}$ However, improved survival rates raise the concern of an increasing number of surviving preterm infants with adverse long-term outcomes. Preterm born children are known to have a higher risk for neurosensory disabilities and cognitive, motor and behavioural problems later in life, especially at low gestational age (GA). ${ }^{3-7}$

\section{What is already known on this topic?}

Long-term outcomes in neonatal intensive care unit survivors are frequently classified as severe, moderate, mild or no impairment.

- Neurodevelopmental impairment (NDI) includes survivors with moderate-to-severe impairment and is the most commonly reported long-term outcome measure in preterm infants, with higher incidence as gestational age decreases.

- In 2010, the Dutch guideline regarding initiation of active treatment in extremely preterm infants was changed, lowering initiation from 25 weeks' to 24 weeks' gestation.

\section{What this study adds?}

- Within a decade after lowering the threshold for supporting active treatment from 25 completed weeks' to 24 completed weeks' gestation, $62 \%$ of the extremely preterm survivors did not have any impairment at 2 years' corrected age.

- The change in threshold and subsequent improvement in survival at 24 weeks have not been accompanied by a large increase in survivors with NDI.

- The percentage of survivors with NDI was comparable for children born at 24 weeks', 25 weeks' and 26 weeks' gestation.

In 2010 a guideline on perinatal treatment of spontaneous extremely preterm birth was implemented in the Netherlands, lowering the threshold for active treatment of preterm infants from 25 completed weeks' to 24 completed weeks' gestation. ${ }^{8}$ As such guideline change regarding initiation of active treatment influences antenatal counselling, mortality and neurodevelopmental outcome, we wanted to provide up-to-date data on neurodevelopmental outcome for infants born below 27 weeks' gestation. ${ }^{9-11}$ Therefore, the nationwide Extremely Preterm Infants - Dutch Analysis on Follow-up (EPI-DAF) Study was set up, in which neurodevelopmental outcome at 2 years' corrected age (CA) was evaluated over a 3-year period using data from the standardised national follow-up programme. ${ }^{12}$ 
The first aim of the study was to classify neurodevelopmental outcome as moderate-to-severe, mild or no impairment-using defined categories of cognitive development, neurological examination and neurosensory function-in NICU survivors stratified for completed weeks of gestation. Children with moderate-tosevere impairment were denoted as survivors with neurodevelopmental impairment (NDI). The second aim was to evaluate which perinatal factors influence NDI and to calculate NDI-free survival relative to live-born and NICU-admitted infants for each GA week.

\section{METHODS}

\section{Patient population}

The EPI-DAF Study included all Dutch live-born infants, born between $24^{0 / 7}$ weeks' and $26^{6 / 7}$ weeks' GA, who were 2 years' CA in 2018-2020. Parents signed informed consent during the follow-up visit for research use of the follow-up data and for transport of data to the Netherlands Perinatal Registry (Perined). ${ }^{13}$

\section{Data collection}

The registry contains linked population-based information concerning pregnancy, delivery and (re)admissions, as registered by midwives, obstetricians and paediatricians/neonatologists. All 10 NICUs export their data to Perined. Follow-up data were uploaded to Perined and linked to historical perinatal data.

Registry data used for this study included birth weight; GA; small for GA (SGA), lower than tenth percentile based on Hoftiezer; ${ }^{14}$ mode of delivery; 5-min Apgar Score; multiplicity; severe necrotising enterocolitis (NEC), defined as pneumatosis intestinalis or perforation; severe brain injury, defined as intraventricular haemorrhage stage 3-4 or severe periventricular leukomalacia grade $2-3$. Socioeconomic status (SES) was areabased and assessed using scores defined by the Netherlands Institute for Social and Cultural Research (The Hague, Netherlands) based on the four-didget postal code at birth, with an average score of 0 and a positive score reflecting higher than average status and a negative score reflecting lower than average status. ${ }^{15}$ Low SES was defined as a score $<-1$, high SES was defined as a score $>+1$.

\section{Follow-up assessment}

Follow-up care is part of standardised aftercare in children after very preterm birth according to the national guideline for follow-up including a standardised follow-up protocol, carried out in all 10 Dutch NICUs. ${ }^{12}$ In principle, parents attend the follow-up clinic attached to the particular NICU their child has been admitted to. At 2 years' CA, this follow-up programme includes assessments by a trained team consisting of a paediatrician/neonatologist, psychologist and physiotherapist, and comprises medical history taking, a physical and neurological examination, and assessment of mental and psychomotor development with the Dutch version of the Bayley Scales of Infant and Toddler Development (Bayley-III-NL, mean 100 (SD 15)). All psychologists and physiotherapists are trained in assessing their scales of the Bayley-III-NL. Parents are asked to fill out the Child Behavioural Checklist (CBL) to rate internalising, externalising and total behaviour problems (mean 50 (SD 10), higher scores indicate more behavioural problems). ${ }^{16}$ Neurological examination was performed to determine cerebral palsy (CP), which was graded using the five levels defined in the Gross Motor Function Classification System (GMFCS), from 1 for minimal impairment to 5 for severe impairment with dependence on caretakers for most daily activities. ${ }^{17}$ A combination of medical history and results of the assessment was used to rate hearing and vision status. Information on maternal education was collected during follow-up and classified as low, middle or high. ${ }^{18}$

\section{Outcome evaluation}

Outcome was classified as moderate-to-severe, mild or no impairment, using defined categories of cognitive development, neurological examination and neurosensory function. ${ }^{451019}$ The entity 'neurodevelopmental impairment' (NDI) was considered in children with a moderate-to-severe impairment. Moderate-tosevere impairment (ie, NDI) included a Bayley-III-NL cognitive composite score <-2 SD, CP (GMFCS level 2-5), functionally impaired vision or blindness, or hearing loss requiring aids or severe sensorineural hearing loss despite aids. Mild impairment included a Bayley-III-NL cognitive composite score between -1 SD and -2 SD, abnormal neurological examination with abnormal neurological signs but with minimal functioning implications (GMFCS 1), mild visual problems (squints or refractive errors) or mild hearing loss (not sufficient to require aids). If no Bayley-III-NL could be performed, the attending neonatologist and psychologist were asked to assess an estimate of cognitive development (no delay, 3-6 months delay or more than 6 months' delay), corresponding with an impairment of none, mild or moderate-to-severe. Outcome classification was based on the worst determinant in either one of the categories. If children did not visit the neonatal follow-up clinic, but a rehabilitation clinic instead due to severe neurodevelopmental problems, they were included in the study classified as moderate-to-severe impairment.

Although cognitive impairments surpass rates of $\mathrm{CP}$ and neurosensory impairment, the quality of motor function and behavioural outcome may also have a significant influence on later impairment. ${ }^{19} 20$ Therefore, outcome was also evaluated including motor development and behavioural outcome in all children in which these scores were available. Motor impairment was scored as moderate-to-severe if the child had a Bayley-III-NL composite motor score $<-2 \mathrm{SD}$, and as mild if the child had a score between -1 SD and -2 SD. Behavioural impairment was scored as moderate-to-severe if one of the composite internalising, externalising or total CBCL T-scores were $>2 \mathrm{SD}$, and as mild if one of the composite scores was between 1 SD and 2 SD

NDI-free survival was calculated relatively to live-born and NICU-admitted infants.

\section{Statistical analysis}

Statistical analysis was performed using R V.3.5.2. Baseline characteristics were compared between GA groups using the oneway analysis of variance or Mann-Whitney $U$ test for continuous variables and using the $\chi^{2}$ test for categorical variables. Maternal education was imputed for $15 \%$ of the children with missing information. Impairment was imputed for all 97 surviving infants who were lost to follow-up. Both variables were imputed using an imputation model containing all baseline characteristics of surviving infants including SES (online supplemental appendix 1) and were imputed using the $\mathrm{R}$ multivariate imputation by chained equation package. Outcome measures were compared between GA groups using a $\chi^{2}$ test. If significant, additional pairwise $\chi^{2}$ tests were performed. Logistic regression was performed for the presence of NDI (moderate-to-severe impairment), including GA, gender, SGA, NEC, severe brain injury and maternal education in the model. A value of $\mathrm{p}<0.05$ was considered statistically significant. 
Table 1 Baseline characteristics of all infants born at <27 weeks' GA who reached 2 years' CA in 2018-2020, and separately for infants born at 24 weeks', 25 weeks' and 26 weeks' gestation

\begin{tabular}{|c|c|c|c|c|c|}
\hline & Total & 24 weeks & 25 weeks & 26 weeks & $P$ value \\
\hline Live born $(\mathrm{N})$ & 991 & 271 & 297 & 423 & \\
\hline Died before admission ( $\mathrm{N}(\%$ of live born)) & $100(10.1)$ & $59(21.8)$ & $24(8.1)$ & $17(4.0)$ & \\
\hline Admitted ( $\mathrm{N}$ (\% of live born)) & 891 (89.9) & $212(78.2)$ & $273(91.9)$ & $406(96.0)$ & \\
\hline Died after admission (N (\% of admitted)) & $240(26.9)$ & $98(46.2)$ & $68(24.9)$ & $74(18.2)$ & \\
\hline Survived to 2 years' CA (N (\% of admitted)) & $651(73.1)$ & $114(53.7)$ & $205(75.1)$ & $332(81.8)$ & \\
\hline Follow-up data available ( $\mathrm{N}$ (\% of survived)) & $554(85.1)$ & $98(86.0)$ & $178(86.8)$ & $278(83.7)$ & \\
\hline Maternal age & $30.3(5.2)$ & $30.7(5.1)$ & $30.6(5.2)$ & $30.1(5.3)$ & 0.437 \\
\hline Birth weight (g) & $820(150)$ & $697(99)$ & $799(120)$ & $876(154)$ & $<0.001 *$ \\
\hline Sex (male) & $288(52.0)$ & $46(46.9)$ & $93(52.2)$ & $149(53.6)$ & 0.524 \\
\hline SGA (<tenth percentile) & $99(17.9)$ & $5(5.1)$ & $27(15.2)$ & $67(24.1)$ & $<0.001^{*}$ \\
\hline Caesarean section & $185(33.4)$ & $14(14.3)$ & $50(28.1)$ & $121(43.5)$ & $<0.001^{*}$ \\
\hline Multiple birth & $154(27.8)$ & $23(23.5)$ & $51(28.7)$ & $80(28.8)$ & 0.573 \\
\hline 5 min Apgar & $7(6,8)$ & $7(5,8)$ & $7(6,8)$ & $7(6,8)$ & $<0.001^{*}$ \\
\hline Severe NEC & $63(11.4)$ & $10(10.2)$ & $21(11.8)$ & $32(11.5)$ & 0.919 \\
\hline Severe brain injury & 85 (15.3) & $15(15.3)$ & $27(15.2)$ & $43(15.5)$ & 0.996 \\
\hline SES & & & & & 0.251 \\
\hline Low & $141(25.5)$ & $25(25.5)$ & $46(25.7)$ & $70(25.3)$ & \\
\hline Intermediate & $338(61.1)$ & $53(54.1)$ & $111(62.4)$ & $174(62.8)$ & \\
\hline High & $74(13.4)$ & $20(20.4)$ & $21(11.8)$ & 33 (11.9) & \\
\hline Maternal education & & & & & 0.100 \\
\hline Low & $63(11.4)$ & $18(18.4)$ & $14(7.9)$ & $31(11.2)$ & \\
\hline Intermediate & $195(35.2)$ & $37(37.8)$ & $58(32.6)$ & $100(36.0)$ & \\
\hline High & $208(37.5)$ & $30(30.6)$ & $78(43.8)$ & $100(36.0)$ & \\
\hline Missing & $88(15.9)$ & $13(13.3)$ & $28(15.7)$ & $47(16.9)$ & \\
\hline
\end{tabular}

Birth weight is presented as mean (SD), Apgar score is presented as median (Q1,Q3), other variables are presented as N (\%). SGA is defined as birth weight below the tenth percentile. A value of $p<0.05$ is considered statistically significant. ${ }^{*}$, significant at 0.05 level

CA, corrected age; GA, gestational age; NEC, necrotising enterocolitis ; SES, socioeconomic status; SGA, small for gestational age.

\section{RESULTS}

\section{Study population}

Within the study period, 991 infants were live born at 24-26 completed weeks' GA, of whom 891 (90\%) were admitted to NICU. Of these, 651 (73\%) infants survived and reached 2 years' CA in 2018-2020, of whom 587 (90\%) were seen for follow-up at 2 years' CA. Fifty-three children did not return for follow-up, parents of eight children refused follow-up and three children were missed due to COVID-19. Thirty-three children did return, but parents declined consent for registering of follow-up data in Perined, resulting in scientific availability of follow-up data at 2 years' CA of $554(85 \%)$ children. No statistically significant differences were seen in baseline characteristics between surviving children with and without follow-up data available, although $37.5 \%$ of the children lost to follow-up were born in families with low SES compared with $25.5 \%$ of the children seen for follow-up (online supplemental appendix table 1). Baseline characteristics of all children with follow-up data available are shown in table 1.

\section{Outcome at 2 years' CA}

Table 2 shows outcome at 2 years' CA, including cognitive Bayley-III-NL cognitive and motor scores, neurosensory function, the results of the neurological exam and CBCL T-scores. Overall, 62\% (95\% CI 58\% to 66\%) had no impairment, $29 \%$ (95\% CI 25\% to 33\%) mild impairment and 9\% (95\% CI 7\% to $12 \%$ ) moderate-to-severe impairment (ie, NDI). Rates of NDI were comparable (around 9\%) between children born at 24 weeks', 25 weeks' and 26 weeks' gestation. Detailed information about the affected domains in children with mild and moderate-to-severe impairment is presented in online supplemental appendix table 2 .

When including Bayley-III-NL motor scores in the definition of impairment, the overall rate of children with NDI increased from $9 \%$ to $13 \%$ (table 2). This increased to $19 \%$ when including CBCL T-scores also in the outcome definition.

Multivariable logistic regression showed that severe brain injury and low maternal education were associated with higher odds on NDI (table 3).

\section{NDI-free survival}

Figure 1 shows imputed overall outcome for all live-born and NICU-admitted infants. For 24 weeks', 25 weeks' and 26 weeks' live-born infants, 38\%, 62\% and 72\% had NDI-free survival up to 2 years' CA, respectively ( $\mathrm{p}<0.001)$. For 24 weeks', 25 weeks' and 26 weeks' NICU-admitted infants, 48\%, 67\% and 75\% had NDI-free survival to 2 years' CA, respectively $(\mathrm{p}<0.001)$.

\section{DISCUSSION}

In 2010, the Dutch practice regarding initiation of active treatment in extremely preterm infants was lowered from 25 completed weeks' to 24 completed weeks' gestation. The EPIDAF Study evaluated neurodevelopmental outcome at 2 years' CA in extremely preterm children born below 27 weeks' gestation, several years after practice change, and found that the change in intervention threshold has not been accompanied by an increase in moderate-to-severely impaired infants. The main findings are that at 2 years' CA, $62 \%$ of survivors did not have impairment, whereas mild impairment was seen in $29 \%$, and 


\section{Original research}

Table 2 Follow-up results of all 554 infants with follow-up data available born $<27$ weeks' gestational age (GA) who reached 2 years' corrected age (CA) in 2018-2020, separately for infants born at 24, 25 and 26 weeks' gestation. All follow-up data are presented as N (\%), mean (SD) or median (IQR). Impairment rates are presented as \% $(95 \% \mathrm{Cl})$. The follow-up programme included a physical and neurological examination and assessment of mental and psychomotor development with the Dutch version of the Bayley Scales of Infant and Toddler Development (Bayley-III$\mathrm{NL}$, mean 100 (SD 15)). Parents are asked to fill out the Child Behavioral Checklist (CBCL) to rate internalising, externalising and total behaviour problems (mean 50 (SD 10), higher scores indicate more behavioural problems). Neurological examination was performed to determine cerebral palsy (CP), which was graded using the five levels defined in the Gross Motor Function Classification System (GMFCS), from 1 for minimal impairment to 5 for severe impairment with dependence on caretakers for most daily activities. A combination of medical history and results of the assessment was used to rate hearing and vision status. Outcome measures were compared between GA groups using a one-way analysis of variance or Mann-Whitney U-test for continuous variables, depending on distribution, and a $\chi^{2}$ test for categorical variables. A value of $p<0.05$ is considered statistically significant

\begin{tabular}{|c|c|c|c|c|c|}
\hline & Total & 24 weeks & 25 weeks & 26 weeks & $P$ value \\
\hline Follow-up data available & $n=554$ & $\mathrm{n}=98$ & $n=178$ & $n=278$ & \\
\hline Bayley-III-NL cognitive score, N (\%) evaluated & $497(89.7)$ & $87(88.8)$ & $162(91.0)$ & $248(89.2)$ & \\
\hline Bayley-III-NL cognitive score mean (SD) & $96(14)$ & $94(12)$ & $95(15)$ & $97(13)$ & 0.107 \\
\hline Bayley-III-NL cognitive score median (IQR) & $96(87-105)$ & $96(87-101)$ & $96(87-101)$ & $96(88-105)$ & 0.135 \\
\hline Bayley-III-NL cognitive score 85 or greater & $404(81.3)$ & $70(80.5)$ & $124(76.5)$ & $210(84.7)$ & 0.073 \\
\hline Bayley-III-NL cognitive score 70-84 & $77(15.5)$ & $12(13.8)$ & $30(18.5)$ & $35(14.1)$ & \\
\hline Bayley-III-NL cognitive score $<70$ & $16(3.2)$ & $5(5.7)$ & $8(4.9)$ & $3(1.2)$ & \\
\hline Bayley-III-NL motor score, N (\%) evaluated & $437(78.9)$ & $80(81.6)$ & $135(75.8)$ & $222(79.9)$ & \\
\hline Bayley-III-NL Bayley motor score mean (SD) & $95(14)$ & $92(15)$ & $97(14)$ & $95(14)$ & $0.037^{*}$ \\
\hline Bayley-III-NL Bayley motor score median (IQR) & $95(84-105)$ & $94(83-101)$ & $98(87-107)$ & $95(87-106)$ & 0.053 \\
\hline Bayley-III-NL Bayley motor score 85 or greater & $326(74.6)$ & $51(63.8)$ & $107(79.3)$ & $168(75.7)$ & 0.093 \\
\hline Bayley-III-NL Bayley motor score 70-84 & $94(21.5)$ & $23(28.8)$ & $25(18.5)$ & $46(20.7)$ & \\
\hline Bayley-III-NL Bayley motor score $<70$ & $17(3.9)$ & $6(7.5)$ & $3(2.2)$ & $8(3.6)$ & \\
\hline Vision, N (\%) evaluated & $533(96.2)$ & $95(96.9)$ & $170(95.5)$ & $268(96.4)$ & \\
\hline Normal & $450(84.4)$ & 79 (83.2) & $140(82.4)$ & $231(86.1)$ & 0.175 \\
\hline $\begin{array}{l}\text { Mild visual problems including squints or } \\
\text { refractive errors }\end{array}$ & $67(12.6)$ & $16(16.8)$ & $23(13.5)$ & $28(10.4)$ & \\
\hline Functionally impaired vision or blindness & $16(3.0)$ & $0(0.0)$ & $7(4.1)$ & $9(3.4)$ & \\
\hline Hearing, N (\%) evaluated & $529(95.5)$ & $94(95.9)$ & $171(96.1)$ & $264(95.0)$ & \\
\hline Normal & $508(96.0)$ & $92(97.9)$ & $162(94.7)$ & $254(96.2)$ & 0.356 \\
\hline Mild hearing loss, not sufficient to require aids & $16(3.0)$ & $2(2.1)$ & $8(4.5)$ & $6(2.3)$ & \\
\hline $\begin{array}{l}\text { Hearing loss requiring aids or severe } \\
\text { sensorineural hearing loss despite aids }\end{array}$ & $5(0.9)$ & $0(0.0)$ & $1(0.6)$ & $4(1.5)$ & \\
\hline Neurological exam, N (\%) evaluated & $530(95.7)$ & $95(96.9)$ & $170(95.5)$ & $265(95.3)$ & \\
\hline Normal & $440(83.0)$ & $72(75.8)$ & $142(83.5)$ & $226(85.3)$ & 0.116 \\
\hline $\begin{array}{l}\text { Mildly abnormal (eg, posture, coordination or } \\
\text { tone dysregulation disorders) }\end{array}$ & $67(12.6)$ & $17(17.9)$ & $24(14.1)$ & $26(9.8)$ & \\
\hline$C P$ & $23(4.3)$ & $6(6.3)$ & $4(2.4)$ & $13(4.9)$ & \\
\hline \multicolumn{6}{|l|}{ Classification of $C P$} \\
\hline Spastic unilateral & $8(34.8)$ & $2(33.3)$ & $0(0.0)$ & $6(46.2)$ & \\
\hline Spastic bilateral & $8(34.8)$ & $2(33.3)$ & $1(25.0)$ & $5(38.5)$ & \\
\hline Atactic & $2(8.7)$ & $2(33)$. & $0(0.0)$ & $0(0.0)$ & \\
\hline Dyskinetic & $1(4.3)$ & $0(0.0)$ & $0(0.0)$ & $1(7.7)$ & \\
\hline Unclassifiable & $4(17.4)$ & $0(0.0)$ & $3(75.0)$ & $1(7.7)$ & \\
\hline \multicolumn{6}{|l|}{ Classification according to GMFCS } \\
\hline GMFCS I & $7(30.4)$ & $3(50.0)$ & $0(0.0)$ & $4(30.8)$ & \\
\hline GMFCS /I & $5(21.7)$ & $1(16.7)$ & $1(25.0)$ & $3(23.1)$ & \\
\hline GMFCS III & $3(13.0)$ & $1(16.7)$ & $0(0.0)$ & $2(15.4)$ & \\
\hline GMFCS IV & $2(8.7)$ & $0(0.0)$ & $0(0.0)$ & $2(15.4)$ & \\
\hline Unknown & $6(26.1)$ & $1(16.7)$ & $3(75.0)$ & $2(15.4)$ & \\
\hline CBCL Total T-score, N (\%) evaluated & $397(71.7)$ & $70(71.4)$ & $130(73.0)$ & $197(70.9)$ & \\
\hline CBCL Total T-score mean (SD) & $48(10)$ & $49(9)$ & $47(10)$ & $48(10)$ & 0.717 \\
\hline CBCL Total T-score median (IQR) & $47(40-55)$ & $47(43-54)$ & $47(39-55)$ & $48(40-56)$ & 0.677 \\
\hline CBCL Total T-score 60 or lower & $358(90.2)$ & $64(91.4)$ & $118(90.8)$ & $176(89.3)$ & 0.605 \\
\hline CBCL Total T-score 61-70 & $34(8.6)$ & $4(5.7)$ & $11(8.5)$ & $19(9.6)$ & \\
\hline CBCL Total T-score $>70$ & $5(1.3)$ & $2(2.9)$ & $1(0.8)$ & $2(1.0)$ & \\
\hline CBCL Internalising T-score, N (\%) evaluated & $398(71.8)$ & $71(72.4)$ & $130(73.0)$ & $197(70.9)$ & \\
\hline CBCL internalising T-score mean (SD) & $47(11)$ & $48(9)$ & $46(11)$ & $47(11)$ & 0.763 \\
\hline
\end{tabular}


Table 2 Continued

\begin{tabular}{|c|c|c|c|c|c|}
\hline & Total & 24 weeks & 25 weeks & 26 weeks & $P$ value \\
\hline CBCL internalising T-score median (IQR) & $45(41-55)$ & $47(41-55)$ & $45(37-55)$ & $45(37-55)$ & 0.712 \\
\hline CBCL internalising T-score 60 or lower & $359(90.2)$ & $66(93.0)$ & $118(90.8)$ & $175(88.8)$ & 0.755 \\
\hline CBCL internalising T-score 61-70 & $33(8.3)$ & $5(7.0)$ & $10(7.7)$ & $18(9.1)$ & \\
\hline$C B C L$ internalising $T$-score $>70$ & $6(1.5)$ & $0(0.0)$ & $2(1.5)$ & $4(2.0)$ & \\
\hline CBCL Externalising T-score, N (\%) evaluated & $398(71.8)$ & $71(72.4)$ & $130(78.0)$ & $197(70.9)$ & \\
\hline CBCL Externalising T-score mean (SD) & $49(10)$ & $50(9)$ & $49(10)$ & $49(10)$ & 0.925 \\
\hline CBCL Externalising T-score median (IQR) & $50(42-56)$ & $48(44-56)$ & $48(42-56)$ & $50(42-56)$ & 0.869 \\
\hline CBCL Externalising T-score 60 or lower & $356(89.4)$ & $66(93.0)$ & $114(87.7)$ & $176(89.3)$ & 0.828 \\
\hline CBCL Externalising T-score 61-70 & $36(9.0)$ & $4(5.6)$ & $14(10.8)$ & $18(9.1)$ & \\
\hline CBCL Externalising T-score $>70$ & $6(1.5)$ & $1(1.4)$ & $2(1.5)$ & $3(1.5)$ & \\
\hline $\begin{array}{l}\text { Impairment, including Bayley-III-NL cognitive score, } \\
\text { vision, hearing and neurological exam, N (\%) } \\
\text { evaluated }\end{array}$ & $554(100)$ & $98(100)$ & $178(100)$ & $278(100)$ & \\
\hline None & $61.9 \%(58-66)$ & $55.1 \%(45-65)$ & $56.7 \%(49-64)$ & $67.6 \%(62-73)$ & 0.072 \\
\hline Mild & $29.1 \%(25-33)$ & $35.7 \%(27-46)$ & $33.7 \%(27-41)$ & $23.8 \%(19-29)$ & \\
\hline Moderate-to-severe & $9.0 \%(7-12)$ & $9.2 \%(5-17)$ & $9.6 \%(6-15)$ & $8.6 \%(6-13)$ & \\
\hline $\begin{array}{l}\text { Impairment, including the above and also Bayley- } \\
\text { III-NL motor score, N (\%) evaluated }\end{array}$ & $464(83.8)$ & $83(84.7)$ & $146(82.0)$ & $235(84.5)$ & \\
\hline None & $53.0 \%(48-58)$ & $43.4 \%(33-54)$ & $51.4 \%(43-59)$ & $57.4 \%(51-64)$ & 0.225 \\
\hline Mild & $34.3 \%(30-39)$ & $43.4 \%(33-54)$ & $35.6 \%(28-44)$ & $30.2 \%(25-36)$ & \\
\hline Moderate-to-severe & $12.7 \%(10-16)$ & $13.2 \%(8-22)$ & $13.0 \%(8-19)$ & $12.3 \%(9-17)$ & \\
\hline $\begin{array}{l}\text { Impairment, including the above and also CBCL } \\
\text { T-scores, N (\%) evaluated }\end{array}$ & $364(65.7)$ & $69(70.4)$ & $118(66.3)$ & $177(63.7)$ & \\
\hline None & $45.6 \%(41-51)$ & $40.6 \%(30-52)$ & $40.7 \%(32-50)$ & $50.9 \%(44-58)$ & 0.249 \\
\hline Mild & $35.7 \%(31-41)$ & $42.0 \%(31-54)$ & $40.7 \%(32-50)$ & $29.9 \%(24-37)$ & \\
\hline Moderate-to-severe & $18.7 \%(15-23)$ & $17.4 \%(10-28)$ & $18.6 \%(13-27)$ & $19.2 \%(14-26)$ & \\
\hline
\end{tabular}

*Pairwise analysis showed a significant difference in Bayley-III-NL motor score between 24 weeks' and 25 weeks' gestation ( $p=0.014$ ).

moderate-to-severe impairment (ie, NDI) in 9\%. The percentage of surviving children with NDI was comparable between 24 weeks', 25 weeks' and 26 weeks' gestation. After multivariable analysis, severe brain injury and low maternal education were associated with higher odds on NDI. NDI-free survival was $48 \%, 67 \%$ and $75 \%$ in NICU-admitted infants at 24 weeks', 25 weeks' and 26 weeks' gestation, respectively.

Comparing our findings with other large national cohort studies from Europe shows lower rates of NDI in the EPI-DAF Study. ${ }^{19} 2122$ However, direct comparison with other studies remains challenging, due to various sources of variation. ${ }^{4}$ This variation is related, for example, to age at assessment, year of birth, socioeconomic conditions and differences in the management of extremely preterm children. One very important issue

\begin{tabular}{ll}
$\begin{array}{l}\text { Table } 3 \text { Logistic regression to evaluate the effect of different } \\
\text { perinatal factors on NDI }\end{array}$ \\
\hline & NDI \\
\hline & OR (95\% CI) \\
\hline GA (days) & $0.98(0.93$ to 1.03$)$ \\
Female & $0.95(0.53$ to 1.79$)$ \\
SGA & $1.47(0.66$ to 3.07$)$ \\
NEC & $1.32(0.51$ to 3.02$)$ \\
Severe brain injury & $2.63(1.32 \text { to } 5.05)^{*}$ \\
\hline Low maternal education & $2.58(1.26 \text { to } 5.03)^{*}$ \\
\hline
\end{tabular}

Numbers are presented as OR with $95 \% \mathrm{Cl}$. Being female was compared with the reference category of being male, low maternal education was compared with a reference category of intermediate-high education. *significant at 0.05 level. GA, gestational age; NDI, neurodevelopmental impairment; NEC, necrotising enterocolitis ; SGA, small for gestational age. that precludes direct comparisons within and between countries is the lack of a consensus definition of NDI, which vary widely across studies. ${ }^{23}$ The current study showed that adding motor function and behavioural data to the outcome definition resulted in a $25 \%$ decrease in children without any impairment at the cost of duplication of survivors with NDI. Note, however, that the percentage of NICU survivors with NDI was comparable between 24 weeks', 25 weeks' and 26 weeks' gestation, independent of the number of domains used for outcome classification. Compared with NDI, there is much less evidence regarding early behavioural, social and emotional outcomes. ${ }^{20}$ However, behavioural impairments may have great impact on attention problems and socioemotional competence in (pre-) school years. For future research, there is a need for more standardised reporting of neurodevelopmental outcomes in very preterm children, which may include a stepwise approach as presented in our study. ${ }^{4}$

The current Dutch approach towards treatment initiation for extremely preterm infants is more conservative than in other countries. ${ }^{2425}$ Also, there is a more restrictive approach towards the continuation of life-sustaining treatment for extremely preterm infants, if there are concerns on potential serious disabilities and the infant's future quality of life. ${ }^{25}$ Both approaches may result in differences in impairment rates. The period spanning from $24^{0 / 7}$ weeks' to $25^{6 / 7}$ weeks' gestation is considered in the Netherlands as a grey zone, in which management of infants born should be decided based on a consensus between the healthcare professionals and the parents, while other countries more often identify this grey zone as a period between 22 weeks and 24 weeks. $^{25} 26$ Differences between hospitals and countries in attitudes towards providing life support to the most immature 
A

Outcome at 2 years in live born infants $(\mathrm{n}=991)$

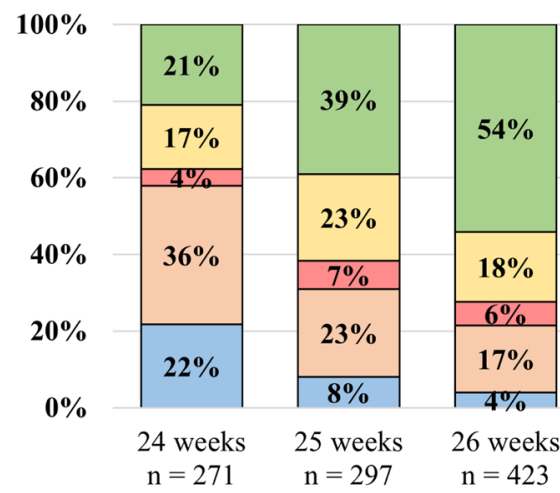

B

Outcome at 2 years in admitted infants $(\mathrm{n}=891)$

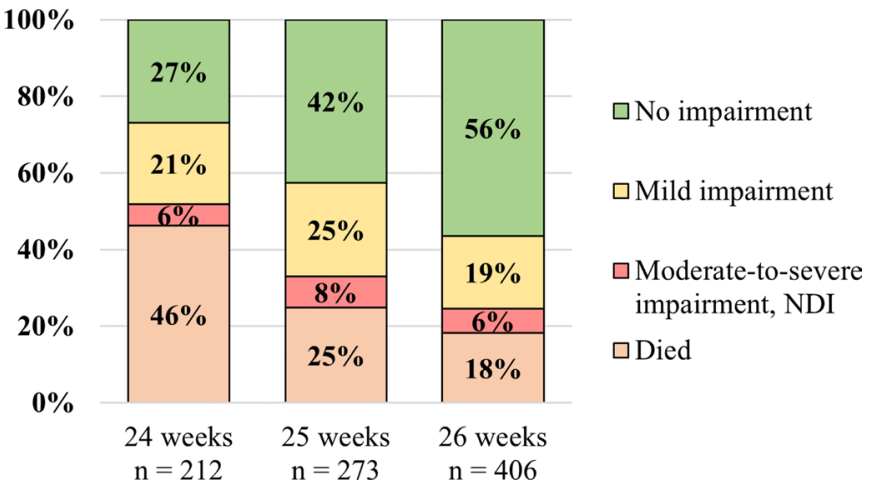

Figure 1 (A) Imputed overall neurodevelopmental outcome, classified as no, mild or moderate-to-severe impairment (ie, NDI), using defined categories of cognitive development, neurological examination and neurosensory function for different GA groups, using all live-born infants as the denominator. (B) Imputed overall neurodevelopmental outcome, classified as no, mild or moderate-to-severe impairment (ie, NDI), using defined categories of cognitive development, neurological examination and neurosensory function, using all NICU-admitted infants as the denominator. GA, gestational age; NDI, neurodevelopmental impairment; NICU, neonatal intensive care unit. Figures might not add up to $100 \%$ due to rounding.

infants seem to have the greatest impact on infants born in this grey zone and less on infants born at 26 weeks' gestation. Unfortunately, our registry does not provide any information on decisions during prenatal counselling and in the delivery room. These decisions might have influenced resuscitation and therefore might have influenced distribution of impairment among infants born at 24 weeks, 25 weeks and 26 weeks.

Although the group of children with moderate-to-severe impairment is clearly defined in the current study, the group of children with mild impairment is heterogeneous. Children with squints or mild refractive errors are similarly classified as children having an IQ-score between 70 and 85, while the latter might have greater impact on educational skills and future life. When classifying children with only mild hearing or vision problems as having no impairment, the rate of children without any impairment would increase from $62 \%$ to $70 \%$. Moreover, children with mild problems in multiple domains are classified as having mild impairment, while they may encounter much more limitations in their socioemotional competence and school career. Therefore, the group of mildly impaired children should be interpreted with caution, all the more because parents and healthcare professionals do not always agree on the perceived impact of impairment. ${ }^{24}$

In the Netherlands, two previous studies on follow-up of extremely preterm infants were performed prior to and just after the 2010 guideline change. ${ }^{27} 28$ The first study reports on neurodevelopmental outcome at 2 years' CA of children born at 25 weeks' and 26 weeks' gestation in a period after lowering the threshold for active treatment from 26 weeks to 25 weeks, showing moderate-to-severe impairment in $17 \%$ and $9 \%$ of infants born at 25 weeks' and 26 weeks' GA, respectively. The second study reports on outcomes at 2 years' CA of children born at 24 weeks' and 25 weeks' gestation in a period directly after lowering the threshold for active treatment from 25 weeks to 24 weeks, reporting moderate-to-severe impairment in $20 \%$ and $12 \%$ for infants born at 24 weeks' and 25 weeks' GA, respectively. These data indicate that lowering the threshold for active treatment over time did not result in increased rates of survivors with NDI.

The current study presents data on neurodevelopmental outcome after preterm birth that can be used for prenatal counselling of parents. However, it is of great importance to adjust the counselling by taking into consideration the parental values and ideas about quality of life. ${ }^{2930}$ As such, the National Institute of Child Health in the UK advises to 'individualise the information to be provided, based on family preferences, wants and needs' ${ }^{31}$ Further exploration is needed on parental views of personalising prenatal counselling and on exactly what aspects of prenatal counselling should be personalised. ${ }^{29}$

The strengths of this study include the high follow-up rate $(85 \%)$, the national approach and the extensive data collection over a period of 3 years in a contemporaneous cohort. Follow-up was performed in a standardised way during regular outpatient clinic visits using a nationwide guideline. ${ }^{12}$ As children lost to follow-up are more often born to parents of lower SES, a multiple imputation model including an SES variable that was available from the registry was used to account for possible selective missing data. However, this study has some limitations as well. We did not have access to a term comparison group. Some other studies adjust the threshold of the composite Bayley scores for the substantially higher mean scores that are often observed in the general population compared with the test norm mean of 100. However, the Bayley-III-NL norms are recently developed and based on a representative population, making it very likely that the current norm of 100 (SD 15) is a realistic assumption. ${ }^{16}$ Second, assessment of the language scale of the Bayley-III-NL is not part of the standardised follow-up programme for extremely preterm infants in the Netherlands. Therefore, language development could not be included in the current study. Furthermore, GA was not blinded for examiners, which might have introduced information bias. Visual and hearing problems were identified using parental information on medical history of the child, which might have resulted in a less precise definition. The national neonatal registry did not contain reliable information on several morbidities, such as antenatal corticosteroids and bronchopulmonary dysplasia. Lastly, neurodevelopmental outcomes at 2 years' CA may significantly underestimate the risk of significant NDI later in childhood. ${ }^{32}$

\section{CONCLUSIONS}

Within a decade after lowering the threshold for supporting active treatment from 25 completed weeks' to 24 completed weeks' gestation, a majority of the surviving preterm infants born before 27 weeks' gestation did not have any impairment at 2 
years' CA. The change in intervention threshold and subsequent improvement in survival at 24 weeks have not been accompanied by a large increase in survivors with NDI. The percentage of survivors with NDI was comparable for infants born at 24 weeks', 25 weeks' and 26 weeks' gestation. Among all live-born and NICU-admitted infants, an increase in NDI-free survival was observed from 24 weeks' to 26 weeks' gestation. This description of a national cohort with high follow-up rates gives an accurate description of the range of outcomes that may occur after extremely preterm birth.

\section{Author affiliations}

'Department of Neonatology, Máxima Medical Center, Veldhoven, Noord-Brabant, The Netherlands

${ }^{2}$ Department of Neonatology, Willem-Alexander Children's Hospital, Leiden University Medical Center, Leiden, The Netherlands

${ }^{3}$ The Netherlands Perinatal Registry, Utrecht, The Netherlands

${ }^{4}$ Department of Neonatology, Beatrix Children's Hospital, University Medical Center Groningen, University of Groningen, Groningen, The Netherlands

Department of Neonatology, Wilhelmina Children's Hospital, University Medical Center Utrecht, Utrecht, The Netherlands

${ }^{6}$ Department of Neonatology, VU University Medical Center, Amsterdam University Medical Center, Amsterdam, The Netherlands

${ }^{7}$ Department of Neonatology, Isala Clinics, Zwolle, The Netherlands

${ }^{8}$ Department of Perinatology, Amalia Children's Hospital, Radboud University Medical Center, Nijmegen, The Netherlands

${ }^{9}$ Department of Neonatology, Erasmus MC Sophia Children's Hospital, Rotterdam, The Netherlands

${ }^{10}$ Department of Neonatology, Maastricht University Medical Centre, Maastricht, The Netherlands

${ }^{11}$ Department of Obstetrics and Gynaecology, Máxima Medical Center, Veldhoven, The Netherlands

${ }^{12}$ Department of Electrical Engineering, Eindhoven University of Technology, Eindhoven, The Netherlands

${ }^{13}$ Department of Neonatology, Emma Children's Hospital, Amsterdam University Medical Centre, Amsterdam, The Netherlands

${ }^{14}$ Department of Neonatology, Máxima Medical Center, Veldhoven, The Netherlands ${ }^{15}$ Department of Applied Physics, School of Medical Physics and Engineering, Eindhoven University of Technology, Eindhoven, The Netherlands

Acknowledgements The EPI-DAF Study group thanks all paediatricians, psychologists, physiotherapists and research nurses who have contributed to the follow-up of extremely preterm infants in one of the 10 perinatal centres in the Netherlands. The authors also thank the parents and children who were involved in the study.

Collaborators The EPI-DAF Study group: Cornelieke Aarnoudse-Moens (Dutch working group on Neonatal Follow-up), Peter Andriessen (steering committee member; project leader EPI-DAF study), Pauline van Beek (PhD student), Lisa Broeders (The Netherlands Perinatal Registry), Henk ter Horst (PI University Medical Center Groningen), Corine Koopman-Esseboom (PI University Medical Center Utrecht), Floris Groenendaal (The Dutch National Neonatal Registry Working Group), René Kornelisse (The Dutch National Neonatal Registry Working Group), Ellen de Kort (PI Máxima Medical Center), Céleste Laarman (PI Amsterdam University Medica Centers location VUmc), Aleid Leemhuis (PI Amsterdam University Medical Centers location AMC), Susanne Mulder-de Tollenaer (PI Isala Clinics), Debbie Nuytemans (Neonatology Network Netherlands), Guid Oei (steering committee member), Wes Onland (Neonatology Network Netherlands), Monique Rijken (steering committee member; Dutch working group on Neonatal Follow-up; PI Leiden University Medical Center), Katerina Steiner (PI Radboud University Medical Center), Renate Swarte (Dutch working group on Neonatal Follow-up; PI Erasmus Medical Center), Elke van Westering-Kroon (PI Maastricht University Medical Center), Ger de Winter (The Netherlands Perinatal Registry)

Contributors PB, MR, AL, PA and the EPI-DAF Study group contributed substantially to the methodological design of the study. MR, HH, CK, EK, CL, SM, KS, RS, EW and AGL contributed substantially to data acquisition, being the principal investigators of the 10 Dutch perinatal centres. PB, MR, LB, AL and PA contributed substantially to the analysis and interpretation of the data. PB wrote the first draft of the manuscript. PA was responsible for the financial funding of the project and supervised the project. PB and PA are guarantors of this study.

Funding This project has been funded by an unrestricted grant from Stichting Tiny \& Anny van Doorne Fonds. The funders had no role in the study design, data collection and analysis, decision to publish, or preparation of the manuscript.

Competing interests None declared.
Patient consent for publication Not applicable.

Ethics approval This study involves human participants and was approved in accordance with the Dutch law on medical research involving human subjects; a waiver (No. N17.166) was provided by the medical ethical committee of Máxima Medical Center (Veldhoven, The Netherlands) and approved by all perinatal centres.

Provenance and peer review Not commissioned; externally peer reviewed.

Data availability statement All data relevant to the study are included in the article or uploaded as supplementary information. Other data may be obtained from a third party and are not publicly available.

Supplemental material This content has been supplied by the author(s). It has not been vetted by BMJ Publishing Group Limited (BMJ) and may not have been peer-reviewed. Any opinions or recommendations discussed are solely those of the author(s) and are not endorsed by BMJ. BMJ disclaims all liability and responsibility arising from any reliance placed on the content. Where the content includes any translated material, BMJ does not warrant the accuracy and reliability of the translations (including but not limited to local regulations, clinical guidelines, terminology, drug names and drug dosages), and is not responsible for any error and/or omissions arising from translation and adaptation or otherwise.

Open access This is an open access article distributed in accordance with the Creative Commons Attribution Non Commercial (CC BY-NC 4.0) license, which permits others to distribute, remix, adapt, build upon this work non-commercially, and license their derivative works on different terms, provided the original work is properly cited, appropriate credit is given, any changes made indicated, and the use is non-commercial. See: http://creativecommons.org/licenses/by-nc/4.0/.

\section{ORCID iDs}

Pauline E van Beek http://orcid.org/0000-0001-8553-3241

Peter Andriessen http://orcid.org/0000-0002-5159-6874

\section{REFERENCES}

1 Stoll BJ, Hansen NI, Bell EF, et al. Trends in care practices, morbidity, and mortality of extremely preterm neonates, 1993-2012. JAMA 2015;314:1039-51.

2 Patel RM, Kandefer S, Walsh MC, et al. Causes and timing of death in extremely premature infants from 2000 through 2011. N Engl J Med 2015;372:331-40.

3 Linsell L, Johnson S, Wolke D, et al. Trajectories of behavior, attention, social and emotional problems from childhood to early adulthood following extremely preterm birth: a prospective cohort study. Eur Child Adolesc Psychiatry 2019;28:531-42.

4 Torchin $\mathrm{H}$, Morgan AS, Ancel P-Y. International comparisons of neurodevelopmental outcomes in infants born very preterm. Semin Fetal Neonatal Med 2020;25:101109.

5 Marlow N, Wolke D, Bracewell MA, et al. Neurologic and developmental disability at six years of age after extremely preterm birth. N Engl J Med 2005;352:9-19.

6 Anderson P, Doyle LW. Neurobehavioral outcomes of school-age children born extremely low birth weight or very preterm in the 1990s. JAMA 2003;289:3264-72.

7 Linsell L, Johnson S, Wolke D, et al. Cognitive trajectories from infancy to early adulthood following birth before 26 weeks of gestation: a prospective, populationbased cohort study. Arch Dis Child 2018;103:363-70.

8 Nederlandse Vereniging voor Kindergeneeskunde, Nederlandse Vereniging voor Obstetrie en Gynaecologie. Richtlijn perinataal beleid bij extreme vroeggeboorte, 2010.

9 Younge N, Smith PB, Gustafson KE, et al. Improved survival and neurodevelopmental outcomes among extremely premature infants born near the limit of viability. Early Hum Dev 2016;95:5-8.

10 Ding S, Lemyre B, Daboval T, et al. A meta-analysis of neurodevelopmenta outcomes at $4-10$ years in children born at 22-25 weeks gestation. Acta Paediatr 2019;108:1237-44.

11 Rysavy MA, Li L, Bell EF, et al. Between-hospital variation in treatment and outcomes in extremely preterm infants. N Engl J Med 2015;372:1801-11.

12 Aanbeveling Landelijke neonatale Follow-up- NICU follow-up. Available: https://www. nvk.nl/

13 Netherlands perinatal registry (Perined). Available: www.perined.nl

14 Hoftiezer L, Hof MHP, Dijs-Elsinga J, et al. From population reference to national standard: new and improved birthweight charts. Am J Obstet Gynecol 2019;220:383. e1-383.e17

15 Netherlands Institute for social research (SCP), SCP Statusscores, 2017. Available: http://www.scp.nl/Formulieren/Statusscores_opvragen [Accessed Mar 2019].

16 van Baar AL, Steenis LJP, Verhoeven M. Bayley-III-NL; technische handleiding. Pearson assessment and information. B.V., Amsterdam, the Netherlands, 2014.

17 Palisano R, Rosenbaum P, Walter $\mathrm{S}$, et al. Development and reliability of a system to classify gross motor function in children with cerebral palsy. Dev Med Child Neurol 1997:39:214-23.

18 Statistics Netherlands, education level. Available: https://www.cbs.nl/en-gb/news/ 2018/20/well-being-not-distributed-equally/education-level [Accessed Nov, 2021]. 


\section{Original research}

19 Serenius F, Källén K, Blennow M, et al. Neurodevelopmental outcome in extremely preterm infants at 2.5 years after active perinatal care in Sweden. JAMA 2013;309:1810-20.

20 Johnson S, Marlow N. Early and long-term outcome of infants born extremely preterm. Arch Dis Child 2017;102:97-102.

21 Moore T, Hennessy EM, Myles J, et al. Neurological and developmental outcome in extremely preterm children born in England in 1995 and 2006: the EPICure studies. BMJ 2012;345:e7961.

22 De Groote I, Vanhaesebrouck P, Bruneel E, et al. Outcome at 3 years of age in a population-based cohort of extremely preterm infants. Obstet Gynecol 2007; 110:855-64.

23 Rysavy MA, Colaizy TT, Bann CM, et al. The relationship of neurodevelopmental impairment to concurrent early childhood outcomes of extremely preterm infants. J Perinatol 2021;41:2270-8.

24 Gallagher K, Martin J, Keller M, et al. European variation in decision-making and parental involvement during preterm birth. Arch Dis Child Fetal Neonatal Ed 2014;99:F245-9.

25 De Proost L, Verweij EJT, Ismaili M'hamdi $H$, et al. The edge of perinatal viability: understanding the Dutch position. Front Pediatr 2021;9:634290.
26 Guillén Úrsula, Weiss EM, Munson D, et al. Guidelines for the management of extremely premature deliveries: a systematic review. Pediatrics 2015;136:343-50.

27 de Waal CG, Weisglas-Kuperus N, van Goudoever JB, et al. Mortality, neonatal morbidity and two year follow-up of extremely preterm infants born in the Netherlands in 2007. PLoS One 2012;7:e41302.

28 Aarnoudse-Moens CSH, Rijken M, Swarte RM, et al. Two-year follow-up of infants born at 24 weeks gestation; first outcomes following implementation of the new 'Guideline for perinatal policy in cases of extreme prematurity'. Ned Tijdschr Geneeskd 2017;161:D1168.

29 De Proost L, Geurtzen R, Ismaili M'hamdi H, et al. Prenatal counseling for extreme prematurity at the limit of viability: a scoping review. Patient Educ Couns 2021;106. doi:10.1016/j.pec.2021.10.033. [Epub ahead of print: 06 Nov 2021].

30 Verweij EJ, De Proost L, Hogeveen M, et al. Dutch guidelines on care for extremely premature infants: navigating between personalisation and standardization. Semin Perinatol 2021;99:151532.

31 British association of perinatal medicine. Perinatal management of extreme.

32 Myrhaug HT, Brurberg KG, Hov L, et al. Survival and impairment of extremely premature infants: a meta-analysis. Pediatrics 2019;143. 